\title{
A novel route to nanostructured bismuth telluride films by electrodeposition
}

\section{Article}

\section{Accepted Version}

Creative Commons: Attribution-Noncommercial-No Derivative Works 4.0

Burton, M. R., Richardson, S. J., Staniec, P. A., Terrill, N. J., Elliott, J., Squires, A., White, N. M. and Nandhakumar, I. S. (2017) A novel route to nanostructured bismuth telluride films by electrodeposition. Electrochemistry Communications, 76. pp. 71-74. ISSN 13882481 doi: https://doi.org/10.1016/j.elecom.2017.02.004 Available at https://centaur.reading.ac.uk/70695/

It is advisable to refer to the publisher's version if you intend to cite from the work. See Guidance on citing.

Published version at: http://dx.doi.org/10.1016/j.elecom.2017.02.004

To link to this article DOI: http://dx.doi.org/10.1016/j.elecom.2017.02.004

Publisher: Elsevier

All outputs in CentAUR are protected by Intellectual Property Rights law, including copyright law. Copyright and IPR is retained by the creators or other copyright holders. Terms and conditions for use of this material are defined in the End User Agreement.

\section{www.reading.ac.uk/centaur}

\section{CentAUR}


Central Archive at the University of Reading

Reading's research outputs online 


\title{
A novel route to nanostructured Bismuth telluride films by electrodeposition
}

\author{
M.R. Burton ${ }^{\ddagger}$, S.J. Richardson ${ }^{\dagger}$, P.A. Staniec ${ }^{\#}$, N.J. Terrill ${ }^{\#}$, J.M. Elliott ${ }^{\dagger}$, A.M. Squires ${ }^{\dagger}$, \\ N.M. White ${ }^{\natural}$ and Iris S. Nandhakumar* \\ *School of Chemistry, University of Southampton, Southampton, SO17 1BJ, UK. Fax: 0238059378 , Tel: +44 \\ 23806877, E-mail: iris@soton.ac.uk \\ ${ }^{\natural}$ Electronics and Computer Science, University of Southampton, S017 1BJ, UK. \\ †Department of Chemistry, University of Reading, Reading RG6 6AD, UK. \\ \# Diamond Light Source, Diamond House, Harwell Science and Innovation Campus, Didcot, Oxon OX11 0DE, \\ UK.
}

\begin{abstract}
We report a novel route to the fabrication of 3D nanostructured stoichiometric bismuth telluride $\left(\mathrm{Bi}_{2} \mathrm{Te}_{3}\right)$ films by electrodeposition through inverse lipid cubic phases as evidenced by Small-angle X-ray Scattering (SAXS) and Helium Ion Microscopy (HIM). The nanostructured $\mathrm{Bi}_{2} \mathrm{Te}_{3}$ films were composed of interconnected nanowires with diameters of $60-150 \AA$.
\end{abstract}

Keywords: Bismuth telluride, nanowire networks, electrodeposition, thermoelectrics

\section{Introduction}

Thermoelectric (TE) materials are an important class of materials that can directly convert thermal waste heat into useful electrical energy using the Seebeck effect [1]. The currently best performing TE materials in commercial TE devices are based on bulk $\mathrm{Bi}_{2} \mathrm{Te}_{3}$ used for refrigeration and waste heat recovery up to $200{ }^{\circ} \mathrm{C}$ [2]. Theoretical calculations by Dresselhaus et al. [3, 4] predict that low dimensional structures such as 1D nanowires or 2D quantum wells systems could dramatically enhance the thermoelectric performance of materials due to quantum confinement effects and enhanced phonon scattering at heterointerfaces that leads to a reduction in the thermal conductivity. This has stimulated considerable interest in the synthesis of $\mathrm{Bi}_{2} \mathrm{Te}_{3}$ nanowires. One widely used approach for producing nanowires of $\mathrm{Bi}_{2} \mathrm{Te}_{3}$ involves deposition (either chemically or electrochemically) into porous anodically etched alumina templates with the smallest electrodeposited nanowires reaching diameters down to $150 \AA$ [5]. Alumina however has a high thermal conductivity of 1.9 $\mathrm{WmK}^{-1}$ [6] which makes TE characterization of the embedded nanowires extremely difficult due to parasitic heat transfer whilst removal of the alumina template requires harsh chemical conditions [7]. Alternatively polymeric membranes with low thermal conductivities (e.g. $0.21 \mathrm{~W} \mathrm{mK}^{-1}$ for polycarbonate) have also been employed as nanotemplates for bismuth telluride nanowire growth [8-11]. Polycarbonate templates can be removed with solvents such as dichloromethane or dimethylformanide, however freestanding nanowires with an aspect ratio of 10 or higher will collapse [7]. 
Zhang and co-workers [12] have reported a non-templated solvo-thermal route to ultrathin $\mathrm{Bi}_{2} \mathrm{Te}_{3}$ nanowires with average diameters of $80 \AA$. This requires temperatures of $160{ }^{\circ} \mathrm{C}$ to produce the separate nanowires; they are then spark plasma sintered at several hundred ${ }^{\circ} \mathrm{C}$ and $50 \mathrm{MPa}$ axial pressure to consolidate the wires into a continuous electrical contact. In contrast, in this manuscript we describe an electrochemical route to a network of ultrathin $\mathrm{Bi}_{2} \mathrm{Te}_{3}$ nanowires with comparable diameters using a 3D cubic lipid phase template. The deposition occurs at room temperature; and the 3D connected end product and the fact that the electrochemical route produces a material already connected to the electrode surface remove the need for a sintering step. This makes our method potentially attractive for use with electrode substrates which either have complex geometries or contain materials not compatible with the high temperatures associated with the sintering processes used by Zhang et al. [12]. In this paper, for example, we describe the deposition of $\mathrm{Bi}_{2} \mathrm{Te}_{3}$ nanowires onto electrodes formed from archival DVDs comprising a layer of gold on a backing of polycarbonate, which softens at $145^{\circ} \mathrm{C}$ [13], and which therefore require relatively mild deposition conditions.

3D cubic lipid phases offer a promising synthetic route to the production of nanowires with diameters $<10 \mathrm{~nm}$ as illustrated for freestanding nanowire networks of platinum $[14,15]$. We hypothesise that the application of these templates instead to thermoelectric semiconductors would open up the possibility of producing nanowires with ultralow diameters for efficient thermoelectric generators [1] that would potentially exhibit an increased Seebeck coefficient due to quantum confinement on the electron density of states [3,4]. Nanowire networks that are composed of highly interconnected nanowires are mechanically stable and can be more easily manipulated and fabricated into devices and potentially exhibit significantly higher thermoelectric performance as predicted by theoretical studies due to a reduction in thermal conductivity via branching [16].

We herein report a novel route to the fabrication of $3 \mathrm{D}$ nanostructured bismuth telluride films that are composed of 60-150 $\AA$ interconnected nanowires. This approach utilises Type II inverse bicontinuous cubic phases $\left(\mathrm{Q}_{\mathrm{II}}\right)^{\mathrm{D}}$ of the lipid phytantriol as templates for electrodeposition. Type II lyotropic liquid crystal systems (LLC) are characterized by an interface that curves towards water and includes the inverse hexagonal phase $\left(\mathrm{H}_{\mathrm{II}}\right)$, containing water cylinders, and the inverse bicontinuous cubic phases (QII), which contain a single lipid bilayer on either side of which lie branching networks of nanometre-sized water channels. There are 3 inverse bicontinuous cubic phases which can form: the 'primitive' $\left(\mathrm{Q}_{\mathrm{II}}^{\mathrm{P}}\right)$, 'double diamond' $\left(\mathrm{Q}_{\mathrm{II}}{ }^{\mathrm{D}}\right)$, and 'gyroid' $\left(\mathrm{Q}_{\mathrm{II}}^{\mathrm{G}}\right)$. The lipid phytantriol forms the $\mathrm{Q}_{\mathrm{II}}^{\mathrm{D}}$ phase in excess water which was used as the template in this work. 


\section{Experimental}

All chemicals were used as received. Phytantriol (3,7,11,15-tetramethyl-1,2,3hexadecanetriol) was purchased from Adina Cosmetics, Bi powder (99.999\%) was purchased from Alfa-Aesar, $\mathrm{TeO}_{2}(99.9995 \%)$ was purchased from Sigma-Aldrich, nitric acid $(70 \%$ laboratory grade) was purchased from Fisher, deionized water was purified by a Milli-Q system to $18.2 \mathrm{M} \Omega \mathrm{cm}$ and ethanol (laboratory grade) was purchased from Fisher. $10 \mathrm{mM}$ $\mathrm{TeO}_{2}$ and $1 \mathrm{M} \mathrm{HNO}_{3}$ electrolytes with $\mathrm{Bi}^{3+}$ concentrations varying from $7.5 \mathrm{mM}$ to $17 \mathrm{mM}$ were produced by adding $3.125 \mathrm{~mL}$ of nitric acid ( $70 \%$ laboratory grade) to $0.0798 \mathrm{~g}$ of $\mathrm{TeO}_{2}$ and between $0.0784 \mathrm{~g}$ and $0.1776 \mathrm{~g}$ of $\mathrm{Bi}$. This was left stirring for 12 hours, or until dissolved. Deionized water was then used to make up to a $50 \mathrm{~mL}$ solution. This was purged for nitrogen for no less than 20 minutes to remove dissolved oxygen.

Nanostructured bismuth telluride films were prepared by potentiostatic electrodeposition from an electrolyte containing $17 \mathrm{mM} \mathrm{Bi}$ and $10 \mathrm{mM} \mathrm{TeO}_{2}$ in $1 \mathrm{M} \mathrm{HNO}_{3}$ through phytantriol modified gold electrodes. The lipid template was applied by dip coating into a solution of ethanol and phytantriol 1:2(w/w). Once dip coated the substrate was left for no less than 30 minutes to allow the ethanol to evaporate, leaving an estimated $22 \pm 1 \mu \mathrm{m}$ thin film of phytantriol coating[14]. The substrate could then be immersed into the electrolyte and left to equilibrate for no less than 30 minutes prior to deposition. Deposition was carried out on Au archival DVDs (Belkin), for SAXS; Au on Si wafers (p-type (llll 0 0) Si wafers with $20 \mathrm{~nm}$ of Ti sputtered, followed by $200 \mathrm{~nm}$ Au sputtered on top), for helium ion microscopy (HIM), scanning electron microscopy (SEM), energy dispersive X-ray spectroscopy (EDX), X-ray diffraction (XRD) and Seebeck characterizations. Au on $\mathrm{Si}$ wafers were sonicated in isopropyl alcohol (IPA) for 10 minutes then washed with deionized water immediately prior to use. The plastic layers of the Au DVDs were separated immediately prior to use. For all substrates, polyimide tape was used to define a working electrode area of $1 \mathrm{~cm}^{2}$ and $\mathrm{Cu}$ tape was used to make contact to the working electrodes. Electrodeposition was carried out using a conventional three electrode configuration. The reference electrode was a saturated calomel electrode (SCE). A Pt mesh was used as a counter electrode, which was flame annealed prior to use to remove any contaminants. After deposition samples were rinsed in deionized water before being submerged in ethanol for 30 minutes to remove the template.

SAXS measurements were carried out at Diamond light source on beamlines; I07 with beam energy and size of $13.0 \mathrm{KeV}$ and $150 \mu \mathrm{m} \times 80 \mu \mathrm{m}$ respectively and $\mathrm{I} 22$ with beam energy and size of $12.4 \mathrm{KeV}$ and $320 \mu \mathrm{m} \times 80 \mu \mathrm{m}$ respectively. Pilatus $2 \mathrm{M}$ detectors were used on both beamlines to collect data over the q range of $0.05 \AA^{-1}$ $0.30 \AA^{-1}$. Calibration was achieved by using a silver behenate sample. Phases were indexed by assigning Bragg peaks to known phases. SEM images were taken on a Zeiss EVO LS25 ESEM microscope and EDX taken using an Oxford Labs attachment for compositional analysis. HIM images were taken on a Zeiss Orion Helium Ion Microscope. XRD patterns were obtained using a Rigaku SmartLab diffractometer using $\mathrm{CuK} \alpha$ radiation. Seebeck coefficients were measured by a custom-made Seebeck measurement unit that was calibrated against a polycrystalline $\mathrm{Bi}$ foil reference standard. 


\section{Results and discussion}

Electrochemical deposition through a thin layer of self-assembled double-diamond phase $\left(\mathrm{Q}_{224}\right)$ of phytantriol was performed over a wide deposition potential window of $-0.375 \mathrm{~V}$ to $-0.05 \mathrm{~V}$ vs SCE and electrolyte bath compositions in order to identify the optimum electrodeposition parameter for generating stoichiometric films as this directly influences their thermoelectric properties. EDX analysis as shown in Figure 1 revealed that stoichiometric $\mathrm{Bi}_{2} \mathrm{Te}_{3}$ films could be prepared from electrolyte solutions composed of $10 \mathrm{mM} \mathrm{TeO}_{2}$ and $17.0 \mathrm{mM}$ Bi dissolved in $1 \mathrm{M} \mathrm{HNO}_{3}$ in the presence of phytantriol. For all other solutions Te rich compositions were obtained, for a stoichiometry close to $\mathrm{Bi}_{2} \mathrm{Te}_{8}$. Variation of the deposition potential over the range $0.375 \mathrm{~V}$ to $-0.05 \mathrm{~V}$ vs SCE was found to have no significant influence on the composition of the electrodeposited films which is consistent with literature reports $[17,18]$.

a)

b)
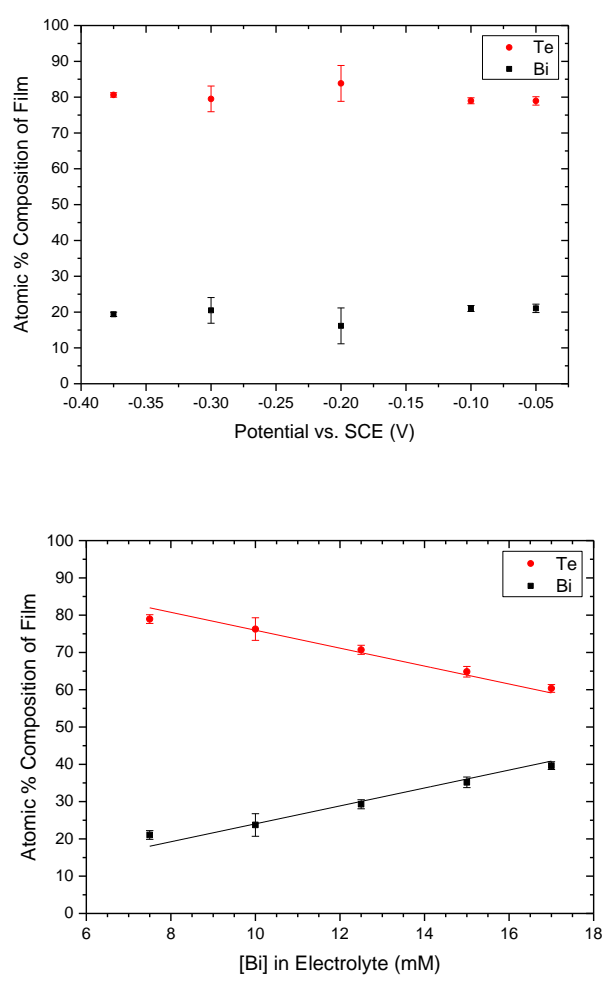


\section{c)}

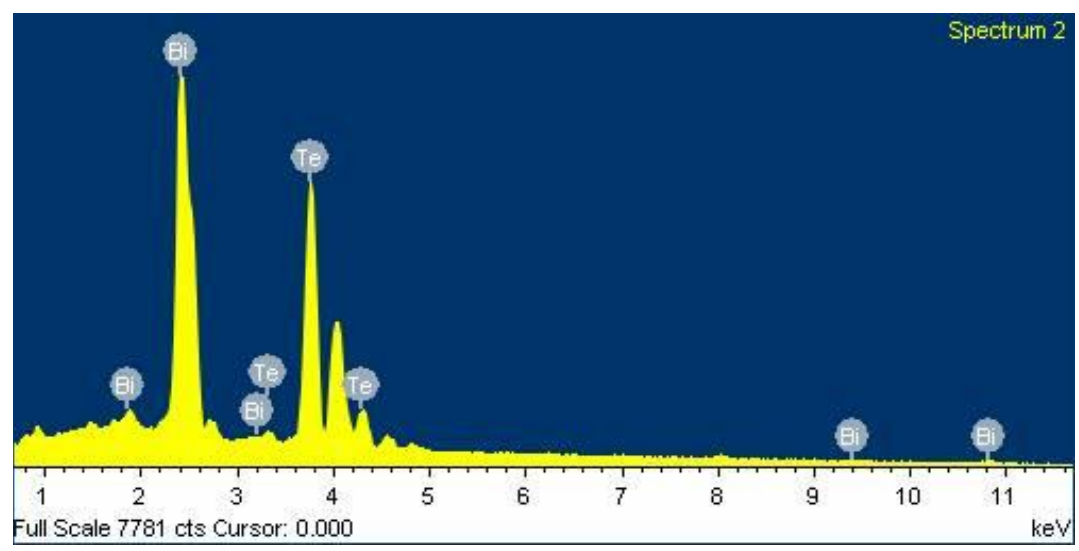

Figure 1. EDX of electrodeposited thin films of Bismuth Telluride. a): deposited from an electrolyte composed of $7.5 \mathrm{mM} \mathrm{Bi}, 10 \mathrm{mM} \mathrm{TeO}_{2}$ and $1 \mathrm{M} \mathrm{HNO}_{3}$, at potentials of $0.375,-0.30,-0.20,-0.10$ and $-0.05 \mathrm{~V}$ vs SCE, $b)$ : deposited from an electrolyte of 10 $\mathrm{mM} \mathrm{TeO}$, and $7.5,10.0,12.5,15.0$ or $17.0 \mathrm{mM}$ Bi dissolved in $1 \mathrm{M} \mathrm{HNO}_{3}$ at a potential of $-0.05 \mathrm{~V}$ vs SCE. Deposition was through phytantriol for a time of $2 \mathrm{~h}$. The linear fits are fixed to intercept at $0 \%$ and $100 \%$ for Bi and Te respectively. Error bars donate the 95\% confidence limits. (c) EDX trace of electrodeposited bismuth telluride film showing the presence of both bismuth and tellurium in the deposits.

Grazing incidence (GI) X-ray diffraction (XRD) data as shown in Figure 2 reveals a series of well-defined and sharp diffraction peaks that can be indexed as belonging to rhombohedral $\mathrm{Bi}_{2} \mathrm{Te}_{3}$ with a space group of $\mathrm{R} 3 \mathrm{~m}$ according to the standard ICDD card (PDF-2/release 2012 RDB). In combination with the EDX analysis presented in Figure 1 these hence provide evidence for the formation of bismuth telluride. The symmetric scan reveals that the electrodeposits are preferentially oriented in the $\left(\begin{array}{lll}1 & 1 & 0\end{array}\right)$ direction which is in agreement with that reported by other studies on high quality bismuth telluride films with good thermoelectric performance [19].

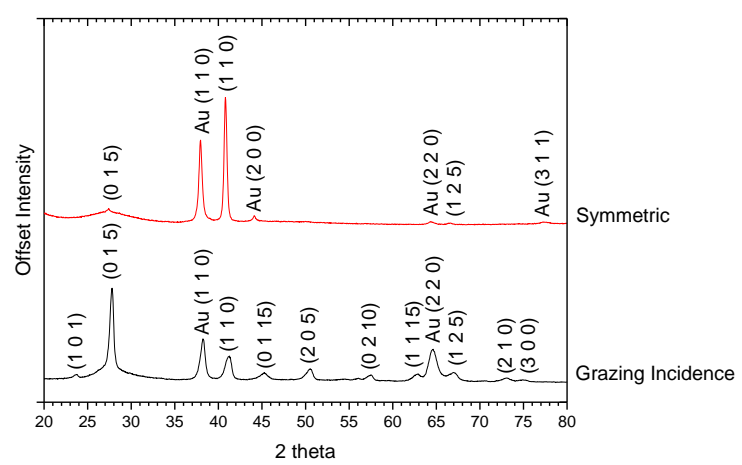


Figure 2. Grazing incidence and symmetric scans of $\mathrm{Bi}_{2} \mathrm{Te}_{3}$ films deposited at $-0.10 \mathrm{~V}$ vs. SCE for $4 \mathrm{~h}$ on Au DVD and $-0.05 \mathrm{~V}$ vs. SCE for $2 \mathrm{~h}$ on Au on Si respectively. The films were deposited in the presence of phytantriol from an electrolyte of $17 \mathrm{mM} \mathrm{Bi}$ and $10 \mathrm{mM}$ $\mathrm{TeO}_{2}$ in $1 \mathrm{M} \mathrm{HNO}_{3}$.

Small angle X-ray scattering (SAXS) in transmission mode and Helium Ion Microscopy (HIM) were then employed to verify and visualize the bismuth telluride nanostructure as shown in Figure 3. 1-D radial SAXS profiles of nanotemplated bismuth telluride films (Fig. 3a) show a single broad Bragg diffraction peak at a $1 / \mathrm{d}$ value of $0.005 \AA^{-1}$. This corresponds to a fairly disordered structure with a characteristic dimension of approximately $200 \AA$.

Representative HIM images of nanotemplated bismuth telluride are shown in Fig. 3b-e. These reveal a somewhat disordered nanostructure that appears to be composed of a 3D network of interconnected nanowires with average diameters ranging from 60-150 $\pm 10 \AA$. The disorder and approximate length scales are consistent with the SAXS pattern. This is a novel finding,

In this paper the $\mathrm{Bi}_{2} \mathrm{Te}_{3}$ material contained a more disordered network of nanowires, whose diameters (60-150 $\AA$ ) were coarser than the water channels in the template (20$30 \AA$ ) but whose materials nonetheless still had $3 \mathrm{D}$ continuous nanowire networks. In order to understand the reason for the more disordered 3D nanostructure with coarser nanowire dimensions, we tested the hypothesis that the bismuth telluride deposition solution altered the structure of the phytantriol template by obtaining SAXS patterns from a gold electrode surface coated in phytantriol in the solution prior to deposition. The 1-D radial SAXS pattern shows four distinct very sharp Bragg peaks, at relative positions for $1 / \mathrm{d}$ in the ratio $\sqrt{2}: \sqrt{3}: \sqrt{ } 4: \sqrt{6}$, representative of the $\mathrm{Q}_{\mathrm{II}} \mathrm{D}_{\text {phase of }}$ phytantriol (space group 224 [20]) indicating that the deposition bath did not alter the template cubic phase structure. 

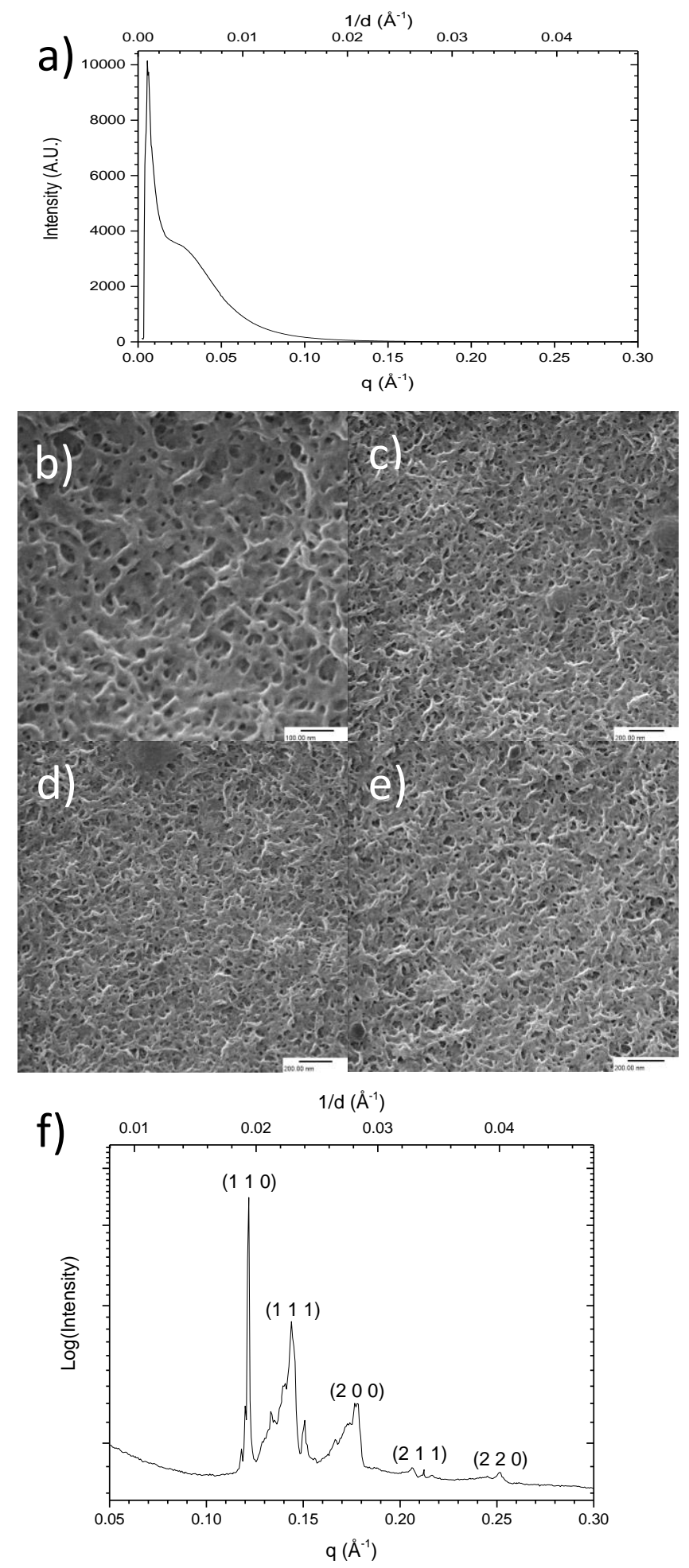

Figure 3. (a) 1D integrated SAXS pattern of a $\mathrm{Bi}_{2} \mathrm{Te}_{3}$ thin film electrodeposited on a phytantriol coated Au DVD. The electrolyte was $17 \mathrm{mM} \mathrm{Bi}$ and $10 \mathrm{mM} \mathrm{TeO}_{2}$ in $1 \mathrm{M}$ $\mathrm{HNO}_{3}$ and the deposition potential was $-0.05 \mathrm{~V}$ vs SCE. (b-e) HIM images of phytantriol-templated $\mathrm{Bi}_{2} \mathrm{Te}_{3}$ film. (f) 1D integrated SAXS pattern of phytantriol 
modified Au DVD electrode placed inside a Kapton windowed cell. The pattern is indexed as $\left(\mathrm{Q}_{\mathrm{II}}\right)^{\mathrm{D}}$ ('double diamond').

Preliminary thermoelectric measurements conducted on stoichiometric nanostructured $\mathrm{Bi}_{2} \mathrm{Te}_{3}$ films prepared from phytantriol with thicknesses of 2-6 $\mu \mathrm{m}$ yielded a Seebeck coefficient of $-88 \mu \mathrm{V} \mathrm{K}^{-1}$. This value is high when compared against literature values of electrodeposited bismuth telluride films with thicknesses in the region of several hundreds of micrometers $[19,21,22]$ which were on average around $-60 \mu \mathrm{V} \mathrm{K}^{-1}$.

\section{Conclusions}

We have demonstrated a new route to the fabrication of $3 \mathrm{D}$ nanostructured stoichiometric bismuth telluride $\left(\mathrm{Bi}_{2} \mathrm{Te}_{3}\right)$ that was prepared by electrodeposition from inverse bicontinuous cubic phases of the lipid phytantriol. The observed nanostructure however is disordered as evidenced by a broad single Bragg diffraction peak in SAXS whilst HIM images exhibit a network of interconnected nanowires with diameters ranging from 60-150 $\AA \mathrm{nm}$. Their formation may be rationalised in terms of electrodeposition through a distorted cubic phytantriol template. Preliminary thermoelectric measurements of the Seebeck coefficient of phytantriol nanotemplated $\mathrm{Bi}_{2} \mathrm{Te}_{3}$ thin films indicate that these are higher than those reported for much thicker electrodeposited bismuth telluride films. In summary nanotemplating via inverse lipid cubic phases provides a promising route for preparing materials with potentially enhanced thermoelectric properties.

\section{Acknowledgements}

We are grateful to Diamond light source for allocation of beam times SM9678, SM1156 and SM14925 and SI10330 on beam lines I22 and I07 respectively. The authors acknowledge the financial support of equipment grant (EP/K00509X/1) for the SmartLab.

\section{References}

1. D.M.Rowe, Ed. In CRC Handbook of Thermoelectrics; CRC Press: New York, 1995.

2. H.J. Goldsmid, Bismuth Telluride and its Alloys as Materials for thermoelectric Generation, Materials, 2014, 7, 2577.

3. L.D. Hicks and M.S. Dresselhaus, thermoelectric Figure of merit of a onedimensional Conductor Phys. Rev. B, 1993, 47, 16631.

4. L.D. Hicks and M.S. Dresselhaus, Effect of Quantum-well Structures on the thermoelectric Figure of Merit, Phys. Rev. B 1993, 47, 12727.

5. J.Martín, C.V. Manzano, O. Caballero-Calero and M. Martín-González, highaspect-ratio and highly ordered $15-\mathrm{nm}$ porous Alumina Templates ACS Appl. Mater. Interfaces 2013, 5, 72. 
6. D.-A. Borca-Tasciuc and G. Chen, anisotropic thermal properties of nanochanneled Alumina Templates, J. Appl. Phys., 2005, 97, 084303.

7. O.Eibl, K. Nielsch, N. Peranio and F. Volklein, Eds. In thermoelectric $\mathrm{Bi}_{2} \mathrm{Te}_{3}$ Nanomaterials, Wiley, Weinheim, 2015.

8. E. Koukharenko, N.M. White, X. Li and I. Nandhakumar, ion-track etched Templates for the high density Growth of Nanowires of Bismuth Telluride and Bismuth Antimony Telluride by Electrodeposition, ECS Trans., 2015, 64, 9.

9. F. Xiao, B. Yoo, K.-H. Lee and N.V. Myung, Electro-transport Studies of electrodeposited $\left(\mathrm{Bi}_{1-\mathrm{x}} \mathrm{Sb}_{\mathrm{x}}\right)_{2} \mathrm{Te}_{3}$ Nanowires, Nanotechnology, 2007, 18, 335203.

10. C. Frantz, N. Stein, Y. Zhang, E. Bouzy, O. Picht, M.E. Toimil-Molares and C. Boulanger, Electrodeposition of Bismuth Telluride Nanowires with controlled Composition in Polycarbonate Membranes, Electrochim. Acta, 2012, 69, 30.

11. O. Picht, S. Müller, I. Alber, M. Rauber, J. Lensch-Falk, D.L. Medlin, R. Neumann and M.E. Toimil-Molares, tuning the geometrical and crystallographic Characteristics of $\mathrm{Bi}_{2} \mathrm{Te}_{3}$ Nanowires by Electrodeposition in ion-track Membranes, J. Phys. Chem. C, 2012, 116, 5367.

12. G. Zhang, B. Kirk, L. A. Jauregui, H. Yang, X. Xu, Y. P. Chen and Y. Wu, rational Synthesis of ultrathin n-type $\mathrm{Bi}_{2} \mathrm{Te}_{3}$ Nanowires with enhanced thermoelectric Properties, Nano Lett 2012 , 12, 56.

13. http://www.polymerprocessing.com/polymers/PC.htm

14. S. Akbar, J.M. Elliott, M. Rittman and A.M. Squires, facile Production of ordered 3D Platinum Nanowire Networks with "single Diamond" bicontinuous cubic Morphology, Adv. Mater., 2013, 25, 1160.

15. S.J. Richardson, M.R. Burton, P.A. Staniec, I. Nandhakumar, N.J. Terrill, J.M. Elliott and A.M. Squires, aligned Platinum Nanowire Networks from surfaceoriented lipid cubic Phase Templates, Nanoscale, 2016, 8, 2850.

16. O. Roslyak and A. Piryatinski, thermoelectric Properties of Semiconductor Nanowire Networks, J. Appl. Phys., 2016, 119, 125107.

17. M. Takashi, Y. Muramatsu, T. Suzuki, S. Sato, M. Watanabe, K. Wakita and T. Uchida, Preparation of $\mathrm{Bi}_{2} \mathrm{Te}_{3}$ Films by Electrodeposition from solution containing Bi-ethylenediaminetetraacetic Acid Complex and $\mathrm{TeO}_{2} \quad \mathrm{~T} . \quad J$. Electrochem. Soc. 2003, 150, C169.

18. M.Takahashi, M.Kojima, S. Sato, N. Ohnisi, A. Nishiwaki, K.Wakita, T.Miyuki, S.Ikeda and Y. Muramatsu, electric and thermoelectric Properties of electrodeposited Bismuth Telluride ( $\left.\mathrm{Bi}_{2} \mathrm{Te}_{3}\right)$ Films, J. Appl. Phys. 2004, 96 (10), 5582.

19. C.J. Boulanger, thermoelectric Material Electroplating: a historical Review, $J$. Electron. Mater., 2010, 39, 1818

20. J. Barauskas and T. Landh, Phase Behavior of the Phytantriol/water System, Langmuir, 2003, 19, 9562.

21. S. Li, M.S. Toprak, H.M.A. Soliman, J. Zhou, M. Muhammed, D. Platzek and E. Müller, Fabrication of nanostructured thermoelectric Bismuth Telluride thick Films by Electrochemical Deposition, Chem. Mat., 2006 , 18, 3627

22. W. Glatz, L. Durrer, E. Schwyter and C. Hierold, novel mixed method for the Electrochemical Deposition of thick Layers of $\mathrm{Bi}_{2+x} \mathrm{Te}_{3-\mathrm{x}}$ with controlled Stoichiometry Electroch. Acta 2008, 54, 755. 